\title{
SURVEILLANCE OF HOSPITAL ACQUIRED BLOODSTREAM INFECTIONS IN NEONATAL INTENSIVE CARE UNIT.
}

\author{
Chirag Modi, M. B. Shah, Sunil Trivedi, Suman Singh
}

1. Assistant Professor, Department of Microbiology, H. M. Patel Centre for Medical Care and Education.

2. Professor \& Head, Department of Microbiology, H. M. Patel Centre for Medical Care and Education.

3. Professor, Department of Microbiology, H. M. Patel Centre for Medical Care and Education.

4. Professor, Department of Microbiology, H. M. Patel Centre for Medical Care and Education.

\section{CORRESPONDING AUTHOR}

Dr. Chirag Modi,

B/117, Shrenik Park,

Opp. Akota Stadium, Productivity Road,

Akota, Vadodara - 390020, Gujarat,

E-mail: chiragmm@charutarhealth.org

Ph: 00919727739203

ABSTRACT: BACKGROUND: Hospital acquired bloodstream infections (BSI) are important cause of morbidity and mortality in Neonatal Intensive Care Unit (NICU) as well as of prolonged hospitalization and additional costs. AIM: The present study was performed to determine the incidence rate and incidence density of hospital acquired BSI in NICU along with their microbiological profile and sensitivity pattern. SETTINGS AND DESIGN: The study was conducted prospectively from $1^{\text {st }}$ May 2009 to $30^{\text {th }}$ June 2010, in the NICU at a tertiary care hospital in Gujarat. METHODS AND MATERIAL: Hospital acquired BSIs were identified according to National Nosocomial Infection Surveillance System (NNIS) definition. The incidence rate was calculated as BSIs per 100 admissions, and incidence density was calculated as BSIs per 1000 patient-days and 1000 central line-days. RESULTS: During the study period 626 neonates were admitted in NICU out of which 40 neonates were positive for hospital acquired BSI with incidence rate of 6.38 per 100 admissions and incidence density of 22.64 per 1000 patient-days. Central line-associated BSI (CLABSI) rate was 57.14 per 1000 central linedays. Klebsiella pneumoniae $(67.5 \%)$ was the predominant isolate with all strains being ESBL producers. CONCLUSIONS: Hospital acquired BSIs in NICU was identified as a significant problem reflecting a need for strict implementation of preventive measures. Inadequate staffing has also been observed in the present study as a predisposing factor to the nosocomial BSIs.

KEY-WORDS: Hospital acquired infections, Bloodstream Infections, Neonates, Intramural, Extramural, Central line.

KEY MESSAGES: Surveillance data are crucial and should become an important component of hospital infection control program in NICU as it provides an overview of our infection control practices.

INTRODUCTION: Patients treated in Neonatal Intensive Care Units (NICUs) are at highest risk for Hospital Acquired Infections (HAIs) ${ }^{1}$ and bloodstream infections (BSIs) are most common in these settings. ${ }^{2,3}$ Surveillance of Hospital Acquired BSIs has proved to be an essential component in infection control and by determining the baseline HAI rates, changes in the rates can be detected and timely measures can be introduced thereby reducing HAI rates, mortality, morbidity and cost. ${ }^{4}$ The purpose of this study was to determine the Hospital Acquired BSIs in 
NICU, which would allow us to generate data for comparison with other NICUs and help us to identify lacunas in infection control practices and improve upon them.

SUBJECTS AND METHODS: The study was conducted in the NICU of a tertiary care hospital in Gujarat from $1^{\text {st }}$ May 2009 to $30^{\text {th }}$ June 2010 following a clearance from Human Research Ethics Committee. Intramural neonates (born within our hospital) and extramural neonates (referred from outside) admitted to the NICU were screened for clinical sepsis according to the definition of Clinical Sepsis provided by Centre for Disease Control and Prevention (CDC) and a primary blood culture was done on admission. BSIs in neonates that became evident after 48 hours of admission were considered as hospital acquired. Neonates with presence of sepsis on admission with a known organism were reviewed after 48 hours of admission and neonates showing presence of sepsis after 48 hours of admission with an organism other than the one that was present during admission, were considered of having hospital acquired BSI. The study excluded those neonates who had evidence of infection being transmitted from mother i.e. those having risk factors like maternal fever of unknown origin, maternal infection, foul smelling vaginal discharge, premature or prolonged rupture of membranes and/or presence of septicemia or showed signs of clinical sepsis and/or with positive blood culture within 48 hours of admission to Neonatal Intensive Care Unit. The neonates were distributed into three birth weight categories as per National Neonatal Perinatal Database (NNPD) ${ }^{5}$ i.e. less than $1000 \mathrm{~g}$ (extremely low birth weight - ELBW), 1000 to $1500 \mathrm{~g}$ (very low birth weight - VLBW), and 1500 to $2500 \mathrm{~g}$ (low birth weight - LBW).

Each day at a specific hour, total number of patients in NICU were counted for the entire study period and summing them up provided 'patient-days'. Patient-days were counted for each month as well as for the entire duration of study period. Similarly central line-days were also calculated. Incidence density of hospital acquired BSIs per 1000 patient-days and Central lineassociated bloodstream infections (CLABSI) per 1000 central line-days were calculated. In addition a central line utilization ratio was also calculated to determine the use in terms of frequency and duration of central line in the NICU and to see how it affected the CLABSI rate.

Number of nursing staff on each day in NICU was also determined for the entire duration of the study period to see whether staff patient ratio had any effect on BSI rates.

RESULTS: During the study period of 14 months a total of 626 neonates were admitted to NICU of which 305 (48.72\%) were born within our hospital (intramural) while 321 (52.28\%) were referred to the hospital from outside (extramural). Forty neonates were positive for hospital acquired BSI and details of these neonates were recorded. The profile of cases positive for hospital acquired BSIs are described in Table 1. The incidence rate and incidence density of hospital acquired BSIs were 6.38 per 100 admissions and 22.64 per 1000 patient-days respectively. The incidence density was highest in month of May 2010 with 76.08 per 1000 patient-days and lowest in the months of December 2009, February 2010, March 2010 and June 2010 where no single positive case was detected. The incidence density for extramural neonates was higher i.e. 24.47 per 1000 patient-days compared to intramural neonates i.e. 18.83 per 1000 patient-days.

The central line-associated BSI (CLABSI) rate was 57.14 per 1000 central line-days for the entire study period. This rate was again higher in extramural neonates i.e. 59.70 per 1000 central line-days compared to 52.63 per 1000 central line-days in intramural neonates. Central 
line utilization ratio for the entire study period was 0.11 and that for the intramural and extramural units were 0.13 and 0.10 respectively.

Gram negative organisms were responsible for most of these infections. Klebsiella pneumoniae $(n=27)$ was the predominant pathogen followed by Enterobacter cloacae $(n=3)$, Candida species ( $n=3)$, Escherichia coli $(n=2)$ and Coagulase negative Staphylococci $(n=2)$. The remaining isolates included Pseudomonas aeruginosa, Burkholderia cepacia and Acinetobacter baumannii, each isolated only once. All Klebsiella pneumoniae isolates were ESBL producers where as five of them were resistant to all antimicrobial agents tested in laboratory including carbapenems.

DISCUSSION: Bloodstream infections are the most common HAIs in neonates ${ }^{6,7,8,9}$ and an important cause of morbidity and mortality, especially in neonates. ${ }^{10}$

In the present study, the overall incidence rate of hospital acquired BSIs was 6.38 per 100 admissions. The rate in the present study was better when compared to previous studies that ranged from 7 - 28 hospital acquired BSIs per 100 admissions. ${ }^{11,12,13,14,15,16 \text { For intramural }}$ neonates this rate was 3.6 per 100 admissions and for extramural neonates it was 9.03 per 100 admissions. This difference was statistically significant $(\mathrm{P}=0.006)$ suggesting that hospital acquired BSIs was more common in extramural neonates. We could not find literature where such rates were compared between intramural and extramural groups. The probable reason for this difference seems to be the immediate intensive care facilities for perinatal morbidities that are not available at the time of delivery conducted at home or in a rural setup thus making these neonates more vulnerable to infections. The average length of hospital stay of positive cases in present study was 15.87 days that also appeared better when compared to previous studies where it ranged from 33 - 98 days. ${ }^{12}, 17,18$ The incidence density of hospital acquired BSI in present study was 22.64 per 1000 patient-days and was higher when compared with previous studies that ranged from $2-10.90$ per 1000 patient-days. ${ }^{13,15}$ This difference could be because a large number of positive cases in present study took discharge against medical advice before they were entirely treated thus affecting the length of stay and thereby the denominator. The incidence density was also observed to be higher in extramural neonates (24.47 per 1000 patient-days) compared to intramural neonates (18.83 per 1000 patient-days). The reason for this difference could be a higher probability of acquiring infections due to a longer hospital stay of extramural neonates compared to intramural neonates in present study as evident by total admissions and total patient-days for each unit (305 admissions and 584 patient-days for intramural unit versus 321 admissions and 1185 patient-days for extramural unit). Length of hospital stay has been documented as a risk factor for acquiring nosocomial infections. ${ }^{9}$ It was also observed that the incidence of hospital acquired BSIs was more when the number of neonates exceeded the number of nurses in the NICU whereas there were no positive cases detected in all those months where this ratio was maintained as 1:1. This suggests that understaffing in NICU could be a contributing factor in hospital acquired BSIs as increase in workload is reflected by poor compliance with hand hygiene and breach of aseptic technique and thereby increasing the risk of transmission of infection. ${ }^{19}$

It was observed that $12(30 \%)$ BSIs were central line associated BSIs (CLABSIs) with an incidence density of 57.14 per 1000 central line-days. Previous studies have shown CLABSI rate ranging from 5.52 - 16.56 per 1000 central line-days. ${ }^{19,20,21}$ Central line utilization ratio for the entire study period was 0.11 that was fairly low when compared with 2004 NNIS report $(0.30)$ whereas the incidence density in present study was much high than 2004 NNIS report (5.52 per 
1000 central line-days) suggesting that the care of central line required a better attention rather than controlling their use.

In contrast to previous study where the mean birth weight of the affected neonates was $1351 \pm 369 \mathrm{~g} 2220(50 \%)$ of positive neonates in present study had a birth weight of 1500 $2500 \mathrm{~g}$ out of which 17 (85\%) belonged to extramural group. This difference could again be attributed to the unavailability of immediate intensive care in this group. In present study 24 $(60 \%)$ of the positive neonates were preterm whereas $16(40 \%)$ were born at full term. Whether this difference was significant or not was not known due to lack of control group although lower gestational age has been associated with late onset sepsis. ${ }^{17}$

Klebsiella pneumoniae was the predominant pathogen isolated accounting for 27 $(67.7 \%)$ of positive cases and was consistent with a previous study ${ }^{23}$ whereas coagulase negative staphylococci has been the predominant pathogen in other studies.12, 21,24 All the Klebsiella pneumoniae isolates were ESBL producers whereas five of them were resistant to all the antimicrobial agents tested including carbapenems.

Eight neonates among the positive cases died during the course of treatment. All these eight neonates were preterm neonates and this group continues to be at risk of mortality as also observed in previous study. ${ }^{12}$ The mortalities could not be attributed to nosocomial sepsis as other comorbidities including low birth weight, congenital heart disease and respiratory distress were also present among these neonates and could have contributed to the outcome.

We concluded that hospital acquired BSI in Neonatal Intensive Care Unit in present study is causing substantial morbidity and mortality and their rates reflect a need for implementation of preventive measures. Implementation of international guidelines for care of central lines, maintaining adequate staffing and continuous training of the staff would be helpful in bringing down the rates. Multi drug resistant Klebsiella pneumoniae continues to be the endemic pathogen in NICU in present study. Formulation of antimicrobial policy for NICU and its strict implementation followed by a regular surveillance and study of their resistance pattern is needed for controlling the spread of antimicrobial resistance in such hospital acquired pathogens.

\section{REFERENCES:}

1. Jarvis WR. Controlling healthcare-associated infections: the role of infection control and antimicrobial use practices. Semin Pediatr Infect Dis 2004;15:30-40.

2. Sohn AH, Garrett DO, Sinkowitz-Cochran RL, Grohskopf LA, Levine GL, Stover BH, et al; Pediatric Prevention Network. Prevalence of nosocomial infections in neonatal intensive care unit patients: Results from the first national point-prevalence survey. J Pediatr 2001;139:821-7.

3. van der Zwet WC, Kaiser AM, van Elburg RM, Berkhof J, Fetter WP, Parlevliet GA, et al. Nosocomial infections in a Dutch neonatal intensive care unit: surveillance study with definitions for infection specifically adapted for neonates. J Hosp Infect 2005;61:300-11.

4. Andrus ML, Horan TC, Gaynes RP. Bennett \& Brachman's Hospital Infections. $5^{\text {th }}$ Ed. Philadelphia: Lippincott Williams \& Wilkins; 2007. Chapter 6, Surveillance of HealthcareAssociated Infections; p.73-90.

5. Deorari AK. National Neonatal-Perinatal Database. New Delhi: All India Institute of Medical Sciences;2005.70 p.

6. Burgner D, Dalton D, Hanlon M, Wong M, Kakakios A, Isaacs D. Repeated prevalence surveys of pediatric hospital-acquired infection. J Hosp Infect 1996;34:163-70. 
7. Gravel D, Matlow A, Ofner-Agostini M, Loeb M, Johnston L, Bryce E, et al; Canadian Nosocomial Infection Surveillance Program. A point prevalence survey of healthcareassociated infections in pediatric populations in major Canadian acute care hospitals. Am J Infect Control 2007;35:157-62.

8. Mühlemann K, Franzini C, Aebi C, Berger C, Nadal D, Stähelin J, et al. Prevalence of nosocomial infections in Swiss children's hospitals. Infect Control Hosp Epidemiol 2004;25:765-71.

9. Lin IJ, Chen $\mathrm{CH}$, Chen PY, Wang TM, Chi CS. Nosocomial infection in a neonatal intensive care unit-from a viewpoint of national health insurance. Acta Paediatr Taiwan 2000;41:123-8.

10. Rahman S, Hameed A, Roghani MT, Ullah Z. Multidrug resistant neonatal sepsis in Peshawar, Pakistan. Arch Dis Child Fetal Neonatal Ed 2002;87:F52-4.

11. Perlman SE, Saiman L, Larson EL. Risk factors for late-onset health care-associated bloodstream infections in patients in neonatal intensive care units. Am J Infect Control 2007;35:177-82.

12. Yalaz M, Cetin H, Akisu M, Aydemir S, Tunger A, Kültürsay N. Neonatal nosocomial sepsis in a level-III NICU: evaluation of the causative agents and antimicrobial susceptibilities. Turk J Pediatr 2006;48:13-8

13. Pawa AK, Ramji S, Prakash K, Thirupuram S. Neonatal nosocomial infection: profile and risk factors. Indian Pediatr 1997;34:297-302.

14. Leibovitz E, Flidel-Rimon O, Juster-Reicher A, Amitay M, Miskin A, Barak Y, et al. Sepsis at a neonatal intensive care unit: a four-year retrospective study (1989-1992). Isr J Med Sci 1997;33:734-8.

15. Apostolopoulou E, Lambridou M, Lambadaridis I. Nosocomial bloodstream infections in a neonatal intensive care unit. Br J Nurs 2004;13:806-12.

16. Ako-Nai AK, Adejuyigbe EA, Ajayi FM, Onipede AO. The Bacteriology of Neonatal Septicemia in Ile-Ife, Nigeria. J Trop Pediatr 1999;45:146-51.

17. Fanaroff AA, Korones SB, Wright LL, Verter J, Poland RL, Bauer CR, et al. Incidence, presenting features, risk factors and significance of late onset septicemia in very low birth weight infants. The National Institute of Child Health and Human Development Neonatal Research Network. Pediatr Infect Dis J 1998;17:593-8.

18. Pessoa-Silva CL, Miyasaki CH, de Almeida MF, Kopelman BI, Raggio RL, Wey SB. Neonatal late-onset bloodstream infection: Attributable mortality, excess of length of stay and risk factors. Eur J Epidemiol 2001;17:715-20.

19. Cimiotti JP, Haas J, Saiman L, Larson EL. Impact of Staffing on Bloodstream Infections in the Neonatal Intensive Care Unit. Arch Pediatr Adolesc Med 2006;160:832-6.

20. National Nosocomial Infections Surveillance System. National Nosocomial Infections Surveillance (NNIS) System Report, data summary from January 1992 through June 2004, issued October 2004. Am J Infect Control 2004;32:470-85.

21. Contreras-Cuellar GA, Leal-Castro AL, Prieto R, Carvajal-Hermida AL. Device-associated infections in a Colombian neonatal intensive care unit. Rev salud publica (Bogota) 2007;9:439-47.

22. Kudawla M, Dutta S, Narang A. Validation of Clinical Score for the Diagnosis of Late Onset Neonatal Septicemia in Babies Weighing 1000 - 2500 g. J Trop Pediatr 2007;54:66-9.

23. Bakr AF. Intravenous Lines-related Sepsis in Newborn Babies Admitted to NICU in a Developing Country. J Trop Pediatr 2003;49:295-7. 
24. Cordero L, Sananes M, Ayers LW. Bloodstream infection in a neonatal intensive care unit: 12 years' experience with an antibiotic control program. Infect Control Hosp Epidemiol 1999; 20:242-6.

Table 1: Profile of positive cases

\begin{tabular}{|c|c|c|c|}
\hline PARAMETERS & INTRAMUIRAL & EXTRAMURAL & TOTAL \\
\hline $\begin{array}{ll}\text { Sex } & \\
- & \text { Male } \\
- & \text { Female }\end{array}$ & $\begin{array}{l}10 \\
1\end{array}$ & $\begin{array}{l}23 \\
6\end{array}$ & $\begin{array}{l}33 \\
(82.5 \%) \\
7(17.5 \%)\end{array}$ \\
\hline $\begin{array}{l}\text { Birth weight } \\
\text { - } \quad<1000 \mathrm{~g} \\
\text { - } \quad 1000-1500 \mathrm{~g} \\
\text { - } 1500-2500 \mathrm{~g}\end{array}$ & $\begin{array}{l}1 \\
7 \\
3\end{array}$ & $\begin{array}{l}1 \\
11 \\
17\end{array}$ & $\begin{array}{l}2(5 \%) \\
18(45 \%) \\
20(50 \%)\end{array}$ \\
\hline $\begin{array}{l}\text { Gestational age } \\
\text { - } \quad \text { Pre term } \\
\text { - } \quad \text { Term }\end{array}$ & $\begin{array}{l}9 \\
2\end{array}$ & $\begin{array}{l}15 \\
14\end{array}$ & $\begin{array}{l}24(60 \%) \\
16(40 \%)\end{array}$ \\
\hline Average hospital stay (days) & 19 & 14 & 16 \\
\hline Average time to development of sepsis (days) & 8 & 6 & 7 \\
\hline BSI per 100 admissions & 3.06 & 9.03 & 6.38 \\
\hline $\begin{array}{l}\text { BSI per } 1000 \text { patient-days } \\
\text { (Total patient-days) }\end{array}$ & $\begin{array}{l}18.83 \\
(584)\end{array}$ & $\begin{array}{l}24.47 \\
(1185)\end{array}$ & $\begin{array}{l}22.64 \\
(1769)\end{array}$ \\
\hline $\begin{array}{l}\text { CLABSI per } 1000 \text { central line-days } \\
\text { (Total central line-days) }\end{array}$ & $\begin{array}{l}52.63 \\
(76)\end{array}$ & $\begin{array}{l}59.70 \\
(134)\end{array}$ & $\begin{array}{l}57.14 \\
(210)\end{array}$ \\
\hline $\begin{array}{l}\text { Central line utilization ratio }=\text { central line-days } / \text { patient- } \\
\text { days }\end{array}$ & 0.13 & 0.11 & 0.11 \\
\hline $\begin{array}{ll}\text { Clinical isolates } \\
\text { - } & \text { Klebsiella pneumoniae } \\
\text { - } & \text { Enterobacter cloacae } \\
\text { - } & \text { Candida species } \\
\text { - } & \text { Escherichia coli } \\
\text { - } & \text { Coagulase negative staphylococci } \\
\text { - } & \text { Pseudomonas aeruginosa } \\
\text { - } & \text { Acinetobacter baumannii } \\
\text { - } & \text { Roultella ornithinolytica }\end{array}$ & $\begin{array}{l}7 \\
- \\
1 \\
1 \\
2 \\
- \\
- \\
-\end{array}$ & $\begin{array}{l}20 \\
3 \\
2 \\
1 \\
- \\
1 \\
1 \\
1\end{array}$ & $\begin{array}{l}27 \\
(67.5 \%) \\
3(7.5 \%) \\
3(7.5 \%) \\
2(5 \%) \\
2(5 \%) \\
1(2.5 \%) \\
1(2.5 \%) \\
1(2.5 \%)\end{array}$ \\
\hline \begin{tabular}{ll}
\multicolumn{2}{l}{ Outcome } \\
- & Recovered \\
- & Referred to other centre \\
- & Discharged against medical advice \\
- & Death
\end{tabular} & $\begin{array}{l}5 \\
- \\
3 \\
3\end{array}$ & $\begin{array}{l}8 \\
1 \\
15 \\
5\end{array}$ & $\begin{array}{l}13 \\
(32.5 \%) \\
1(2.5 \%) \\
18(45 \%) \\
8(20 \%)\end{array}$ \\
\hline
\end{tabular}

